\title{
Pulmonary function in beryllium workers: assessment of exposure
}

\author{
D KRIEBEL,' NANCY L SPRINCE, ${ }^{2}$ ELLEN A EISEN, ' I A GREAVES' \\ From the Occupational Health Program,' Harvard School of Public Health, and the Department of Medicine \\ (Pulmonary Unit), ${ }^{2}$ Massachusetts General Hospital, and Harvard Medical School, Boston, MA 02115, USA
}

\begin{abstract}
The inhalation of beryllium causes a serious lung disease characterised by pronounced radiographic and functional impairments and occurs in workers engaged in the extraction and manufacture of the metal. This paper describes the beryllium exposure levels and refining processes in a large beryllium factory operating since the 1930s. Lifetime beryllium exposure histories were estimated for the 309 workers present at a health survey conducted in 1977. Beryllium exposure levels in the plant were high for many years, with some estimated exposure levels in excess of $100 \mu \mathrm{g} / \mathrm{m}^{3}$. As late as 1975 , there were exposures to beryllium above $10 \mu \mathrm{g} / \mathrm{m}^{3}$ in some jobs. After about 1977 , the plant was in compliance with the permissible exposure limit of $2.0 \mu \mathrm{g} / \mathrm{m}^{3}$. The median cumulative exposure in this cohort was $65 \mu \mathrm{g} / \mathrm{m}^{3}$-years and the median duration of exposure was 17 years. From these data a series of exposure parameters, functions of the exposure histories that characterise biologically important dimensions of exposure were calculated for each worker.
\end{abstract}

Beryllium disease of the lung is a serious, potentially disabling, granulomatous disorder caused by inhaling particles of beryllium compounds. ' Numerous studies and case reports have described this disease, its occurrence in workers exposed to various beryllium compounds, its clinical course, and treatment. ${ }^{2}$ The subclinical effects of beryllium are less well studied. It is not well established, for example, whether exposed workers who do not develop the chronic disease suffer any ill effects from their exposure. Only a few studies have looked for such effects. ${ }^{3-5}$ The present study is the largest yet published on the subclinical effects of beryllium.

Since 1977, the production workers at a large beryllium plant have been examined every three years by a team from the Massachusetts General Hospital lead by one of the authors (NLS). All cooperating production workers performed spirometry, and a posteroanterior chest radiograph 'and blood gas measurements, and answered a standardised questionnaire for respiratory symptoms. Lifetime beryllium exposure histories were estimated for each worker participating in the health surveys based on estimates of air concentrations of beryllium in the plant from 1935 to 1977.

Accepted 9 February 1987
We describe operations at the plant, the various processes necessary in extracting beryllium from its ore, details of workers' exposures, and the derivation of exposure parameters used to assess exposure response relations. Health effects data are presented in a companion paper. ${ }^{6} \mathrm{~A}$ detailed reconstruction of lifetime exposure histories has never been published for a large beryllium plant, and it is hoped that this paper, its companion, ${ }^{6}$ and others to follow will improve understanding of this important occupational disease.

\section{Materials and methods}

PLANT HISTORY AND OPERATIONS

The study plant is a large beryllium extraction and manufacturing facility which, at various times in its 50 year history, has produced most of the beryllium refined in the United States. The plant began operations in 1934, and by 1938 the company had installed rolling and drawing equipment to supply beryllium alloys in various forms: sheet, strip, wire, and tubing. The principal product has always been beryllium copper alloys-the "master" alloy containing 4\% beryllium and other forms containing $2 \%$ or less beryllium. Other products have included various other beryllium alloys, pure beryllium metal, and beryllium oxide. In 1943 the plant employed about 500 production workers; in 1975 there were about $350{ }^{8}$ 


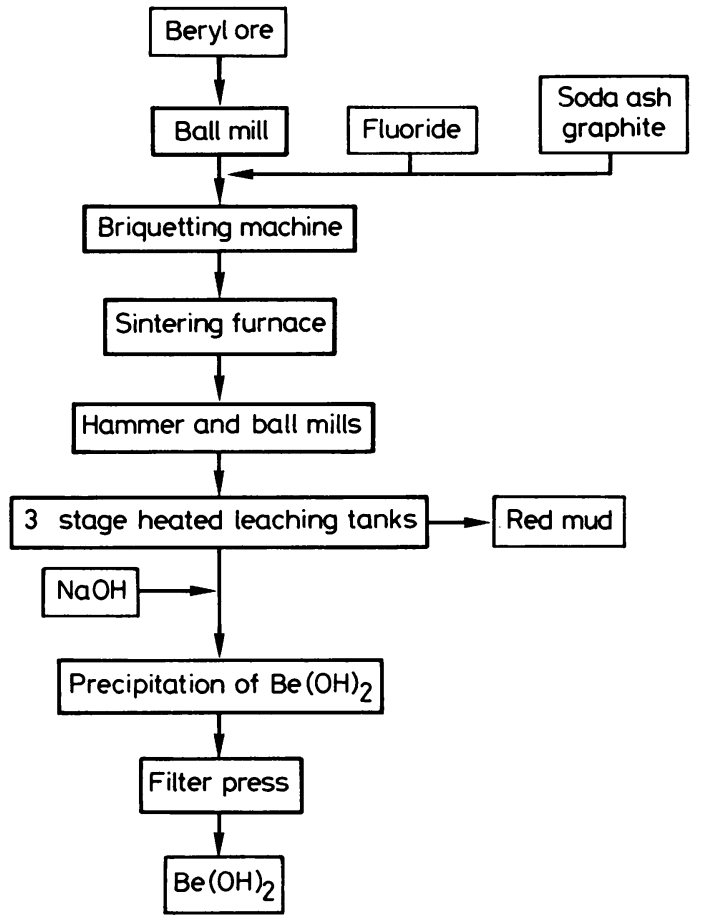

Fig 1 Major steps in extraction of beryllium from beryl ore.

EXTRACTION AND MANUFACTURING PROCESSES The first phase of the production process in the plant is the extraction of beryllium hydroxide from the beryllium ore ${ }^{9-11}$ (fig 1). The ore is ground in a ball mill, mixed with fluoride (either sodium fluoroferrate or sodium silicofluoride), and formed into briquettes. The briquettes are fed to a sintering furnace where they are kept for about two hours during which time a soluble beryllium fluoride is produced. The sintered briquettes are cooled, crushed, ground, and then leached in water to bring the beryllium salt into solution. The settled "red mud" is discharged, and sodium hydroxide is added to the solution to precipitate insoluble beryllium hydroxide which is then recovered in a filter press. Since about 1964, this initial extraction process has not been performed at the plant; beryllium hydroxide was shipped in from elsewhere, firstly from another plant of the same company and later from other sources.

The second phase of the process leads to the production of various metal products ${ }^{9}$ (fig 2). Beryllium hydroxide is loaded into a furnace and calcined at $900^{\circ} \mathrm{C}$ to yield beryllium oxide $(\mathrm{BeO})$. The $\mathrm{BeO}$, a fine white powder, is bagged (originally by hand but now mechanically), loaded into an electric arc furnace, and kept at about $1800^{\circ} \mathrm{C}$; carbon and copper are also added to the furnace. The $\mathrm{BeO}$ is reduced to beryllium metal which combines with copper to form the alloy. Ingots of beryllium copper are poured, cooled, and sent to another furnace for the addition of more copper to bring the beryllium concentration down to the desired percentage. The beryllium copper is poured into "pigs" for sale to

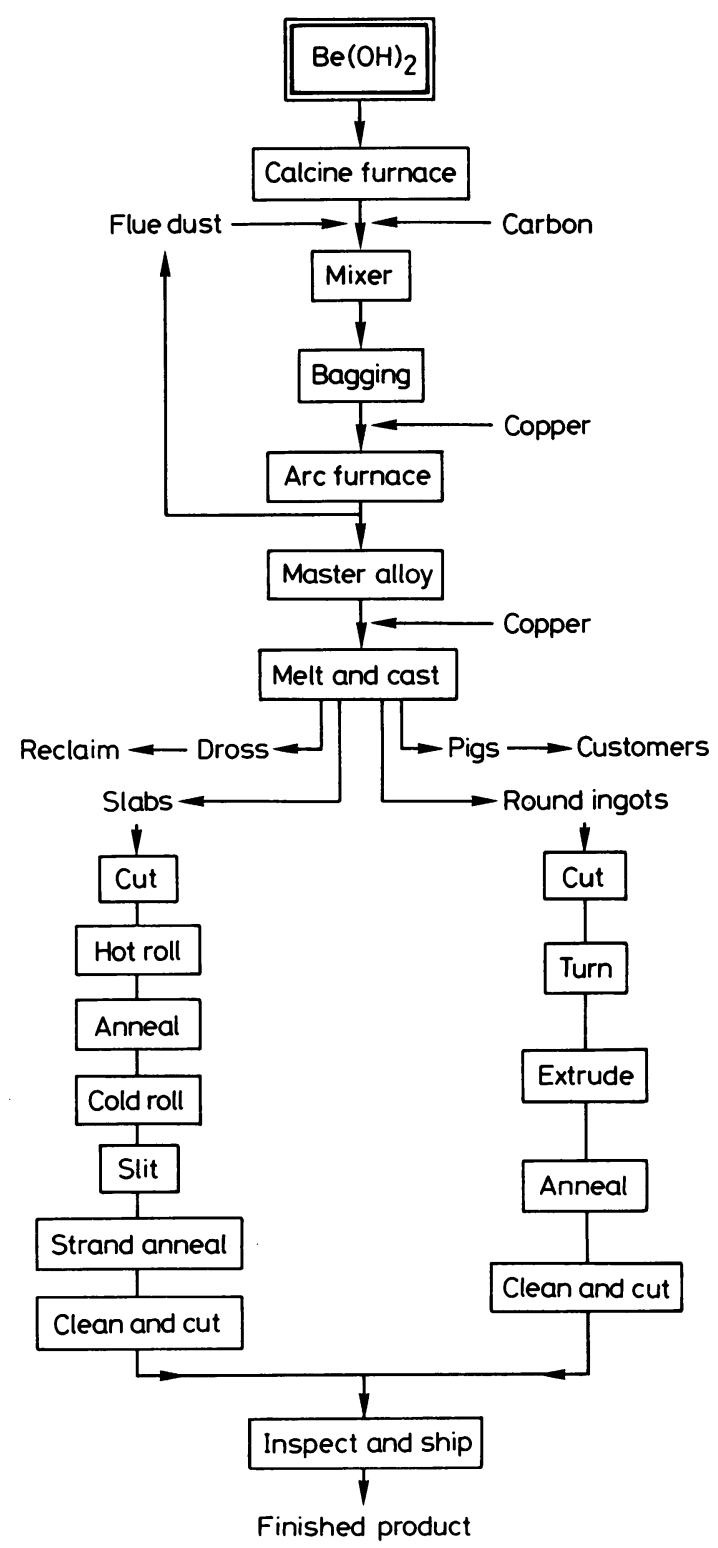

Fig 2 Major steps in beryllium-copper alloy fabrication. 
metal manufacturers, or cast into slab or round ingots. The ingots are rolled, turned, and extruded to form various shapes, such as sheets, rods, wire, and tubing. These products are annealed by heating, then cleaned in a pickling operation to remove surface contamination. Final steps are trimming, slitting, cutting, and grinding into finished sizes.

\section{INDUSTRIAL HYGIENE DATA}

Beryllium exposures at this plant were measured by two principal methods: the Atomic Energy Commission (AEC) method and the personal sampling method.

The AEC method, the original method by which beryllium was sampled, is still considered the standard. ${ }^{1213}$ This technique has been in use since 1950 , and was formalised in 1956 as an appendix to the sales contract between the AEC and its beryllium suppliers. ${ }^{12}$ Also, the $2.0 \mu \mathrm{g} / \mathrm{m}^{3}$ air standard was based on measurements made with this method, and so health and safety personnel have been reluctant to change to a different method even though personal sampling is today the standard technique for most other toxic substances.

Air samples were collected with a high volume sampler ( 20 cubic feet/minute) on 4 inch No 41 Whatman filter paper; samples were collected either in the breathing zone of a worker for periods of two to five minutes or in a general work area for longer periods. Results of sampling were used with a time study of each job to construct daily weighted average (DWA) exposure measurements. The use of the acronym DWA, rather than the more standard TWA, emphasises that the data were derived from short term samples, weighted on the basis of a time study, and not from a full shift personal sample. One advantage of the DWA method is that samples may be taken for brief operations that have the potential for high exposure. In a full workshift sample such brief exposures would be lost in the overall average for the day. The method measures exposures for jobs rather than for individual workers. Non-routine tasks are difficult to study by this method.
Personal sampling, a more recent method, was used in some surveys of the plant (table 1). ${ }^{12}$ Personal samples were collected either over a full shift or a large part of the shift. Battery operated pumps were attached to a worker's belt and a $37 \mathrm{~mm}$ membrane filter to the collar. Results were expressed as an eight hour time weighted average (TWA). Two types of samples were collected: total particulate samples for which the above apparatus was used and respirable particulate samples for which a miniature cyclone was attached upstream from the filter to remove non-respirable particles. $^{12}$ For the present paper, only the total particulate samples were considered when converting exposure measurements collected by personal sampling to DWAs because the AEC method also collected total particulates without regard to size.

Until recently, samples were analysed for beryllium by the Morin fluorimetric method. ${ }^{14}$ Now the measurement is performed by atomic absorption analysis. ${ }^{15}$ Both methods are accurate, reproducible, and yield comparable results.

Industrial hygiene data have been collected at various times by different government agencies (table 1) using either the AEC or personal sampling method. ${ }^{810111617}$ In addition, several studies have been performed in which side by side samples were collected by the different sampling methods. ${ }^{12}$ Donaldson summarised these studies and provided data on the correlations among methods ${ }^{12}$ (and unpublished data). The correlation coefficient between the AEC and personal sampling methods was $0 \cdot 5$. A DWA of $2 \cdot 0$ $\mu \mathrm{g} / \mathrm{m}^{3}$ calculated by the AEC method was approximately equivalent to a TWA by the total dust personal sampling method of $4 \mu \mathrm{g} / \mathrm{m}^{3}$. Based on these calculations, a conversion factor of 0.5 was applied to total particulate personal TWAs to estimate the DWAs that would have been calculated by the AEC method. All estimated DWAs were considered precise only to the nearest $\mu \mathrm{g} / \mathrm{m}^{3}$.

At least 2000 air samples were made in the plant beginning in 1947; however, for most surveys only the geometric mean levels in each job or department surveyed were available. A geometric mean air level

Table 1 Industrial hygiene data sources

\begin{tabular}{|c|c|c|c|c|c|}
\hline Source & $\begin{array}{l}\text { Type of } \\
\text { sampling }\end{array}$ & Dates & $\begin{array}{l}\text { Used to represent } \\
\text { the years }\end{array}$ & $\begin{array}{l}\text { No of jobs/ } \\
\text { depts surveyed }\end{array}$ & Reference \\
\hline $\begin{array}{l}\text { Pennsylvania Dept of Health } \\
\text { Atomic Energy Commission } \\
\text { Pennsylvania Dept of }\end{array}$ & $\begin{array}{l}\text { DWA* } \\
\text { DWA }\end{array}$ & $\begin{array}{l}1947-54 \\
1961\end{array}$ & $\begin{array}{l}1935-60 \\
1955-69\end{array}$ & $\begin{array}{l}26 \\
41\end{array}$ & $\begin{array}{l}10 \\
11\end{array}$ \\
\hline Environmental Resources & PSt & 1972 & $1961-76$ & 95 & 16 \\
\hline $\begin{array}{l}\text { National Institute for } \\
\text { Occupational Safety and Health } \\
\text { Management surveys }\end{array}$ & $\begin{array}{l}\text { PS } \\
\text { DWA }\end{array}$ & $\begin{array}{l}1975 \\
1980\end{array}$ & $\begin{array}{l}1970-76 \\
1977-83\end{array}$ & $\begin{array}{r}58 \\
114\end{array}$ & $\begin{array}{r}8 \\
17\end{array}$ \\
\hline
\end{tabular}

*Daily weighted average concentration (see text).

+Personal sampling concentration (see text). 
was estimated for each job, either using the mean reported by the authors of a survey, or calculating one directly when individual sample results were available.

\section{CALCULATION OF LIFETIME EXPOSURE TO BER YLLIUM}

A standardised set of job titles was developed, relying in part on earlier efforts by NIOSH (unpublished data) and in part on a reconstruction of the departments and operations at this plant. One hundred and two unique jobs were identified in the plant from company records, from work histories of the workers, and from various industrial hygiene reports. Typically three data points were available for a given job, one covering the period up until about 1960 , one for the 1960s and early 1970s, and one for the late 1970 s. For each job, a beryllium DWA exposure was estimated using the data sources in table 1 and covering all years in which the job was active. Not all of these jobs existed in all years of the plant's operation.

Work histories were collected on each worker at health examinations in 1977, 1980, and 1983, and these provided the years each worker was employed in each job. The workers were presented with a matrix listing each department in the plant versus each year since 1935. Workers were asked to check the boxes indicating which departments they were in for each year, and to note the exact job title. If a worker reported more than one job in a year, the year was apportioned evenly among the different jobs. Each worker's job matrix was checked for completeness by an interviewer.

From the beryllium exposures in each job in each year of the plant's operation, and each worker's year by year job histories, beryllium DWAs were estimated for each year of the worker's employment up until $1977 . .^{18}$

\section{MODELLING EXPOSURE PARAMETERS \\ Biology}

The selection of exposure parameters for use in studying the exposure response relation of beryllium was based on the physiological mechanisms of the disease. Beryllium disease results from the effects of two separate but reinforcing mechanisms: an acute inflammatory effect and a cell mediated immune response.' This model has several implications for epidemiology (table 2). For example, both acute and chronic effects of exposure are anticipated, suggesting that both recent and long term exposures may affect the lung; hypoxaemia has been reported to be an early effect of beryllium in $\operatorname{dogs}^{19}$ and man, ${ }^{3}$ whereas fibrosis might be expected to develop more slowly and be caused by exposure over many years. Secondly, the inflammatory and immune mechanisms may have different dose response curves, resulting in a combined dose response curve that is complex. In particular, it is
Table 2 Aspects of beryllium pulmonary toxicity important for epidemiological investigations

\begin{tabular}{ll}
\hline Characteristic & Implications for epidemiology \\
\hline Acute effects & $\begin{array}{c}\text { Known to exist. Recent exposure may } \\
\text { be the main determinant of these } \\
\text { effects } \\
\text { Long term exposure may be most } \\
\text { important, separate effects of } \\
\text { intensity and duration are possible } \\
\text { May exist for some health effects but } \\
\text { duration of latent period is unknown } \\
\text { Latency }\end{array}$ Poor clearance from the lung. Immune \\
status (below) may alter rate of \\
clearance
\end{tabular}

plausible to assume that exposures received at different intensities (the concentration of beryllium inhaled) may have very different potencies: exposure at low levels might not trigger an immune response in a worker with no previous exposure but might cause mild inflammatory changes. If this same worker became sensitised to beryllium by a sufficiently intense exposure, however, then subsequent exposure even at a very low level might be toxic. Each of these possibilities has implications for the way in which exposure should be characterised in an exposure response model, and because it was not possible a priori to identify a single "best" parameter, several different exposure parameters were developed and tested in exposure response models.

\section{Exposure vectors}

Individual exposure histories were constructed as described above. For each worker, this information was used to construct a vector in which the elements of the vector represented the estimated annual exposure to beryllium in each year of the worker's employment in the plant. The exposure estimates are eight hour concentrations.

Exposure vector for worker $\mathrm{i}$ was defined as follows:

$$
\left(E_{i}\right)=\left\{e_{i j}\right\}=\left\{e_{i 1}, e_{i 2}, e_{i 3}, \ldots e_{i n_{i}}\right\}
$$

where $e_{i j}=$ exposure level (expressed as DWA) for worker $i$ in time periods, $j=1,2,3 \ldots n_{i}$, and $n_{i}$ is the number of years of employment of worker $i$.

An exposure parameter is a mathematical function of the exposure vector. Consider the general form for a linear model of exposure response relations:

$y_{i}=\beta_{0}+\sum_{k=1}^{m} \beta_{k} X_{i k}+\beta_{m+1} f\left(E_{i}\right)$

where $y$ is an outcome measure, $\left(x_{k} \ldots x_{m}\right)$ are con- 
founders or effect modifiers, and $\mathrm{f}$ is a function of the exposure vector. For example, cumulative exposure (CE) may be derived from the exposure vector:

$\mathrm{CE}=\sum_{j=1}^{\mathrm{n}_{\mathrm{i}}} \mathrm{e}_{\mathrm{ij}}$,

The strategy for constructing exposure parameters in the present study was to separate out the time and intensity features of exposure by partitioning cumulative exposure into components. Each parameter may then be evaluated conditionally on all covariates in the exposure response model.

\section{Partitioning exposures by time}

The same levels of exposure received at different times during the period of employment may have different potencies. To account for these time related differences, an exposure response model was used to estimate separately the associations between lung function and exposures that were received at different times before the health survey. Cumulative exposure was divided into three components representing the sum of annual exposures in three periods ( 1 to 10,11 to 20 , and 21 or more years before the health survey in 1977). These three parameters were:

$$
\begin{aligned}
& C E_{1-10}=\sum_{j=1}^{10} e_{i j}, \\
& C E_{11-20}=\sum_{j=11}^{20} e_{i j}, \text { if } n_{i}>10, \\
& C E_{\geqslant 21}=\sum_{j=21}^{n_{i}} e_{i j}, \text { if } n_{i}>20,
\end{aligned}
$$

A given worker's cumulative exposure was therefore represented by the sum of his $\mathrm{CE}_{1-10}, \mathrm{CE}_{11-20}$, and $\mathrm{CE}_{\geqslant 21}$. By constructing exposure response models using these time partitioned cumulative exposures, it was possible to examine differences in the statistical measures of association between beryllium exposures at different times and measures of lung function (equation 6).

$$
\begin{aligned}
y=b_{0}+\sum_{k=1}^{m} b_{k} x_{k}+b_{m+1} C E_{1-10}+ \\
b_{m+2} C E_{11-20}+b_{m+3} C E_{\geqslant 21}
\end{aligned}
$$

Partitioning exposures by intensity

Cumulative exposure was partitioned also by the intensity of exposures. Unless the dose response curve is linear, and the assumptions of cumulative exposure (see above) hold, exposures received at different intensities may have different potencies. To allow for this, exposures received at different levels of intensity may be entered separately into the exposure response model. A pair of exposure parameters coding for exposures above or below $25 \mu \mathrm{g} / \mathrm{m}^{3}$ are shown in the following equations.

$$
\begin{aligned}
& \text { Intensity }_{<25}=\sum_{j=1}^{n_{i}} e^{\prime}{ }_{i j}, \text { where } e^{\prime}{ }_{i j}=\begin{array}{l}
e_{i j} \text { if } e_{i j}<25, \\
0 \text { if } e_{i j} \geq 25,
\end{array} \\
& \text { Intensity }_{\geqslant 25}=\sum_{j=1}^{n_{i}} e^{\prime \prime}{ }_{i j}, \text { where } e^{\prime \prime}{ }_{i j}=\begin{array}{l}
0 \text { if } e_{i j}<25 \\
e_{i j} \text { if } e_{i j} \geq 25
\end{array}
\end{aligned}
$$

Again, a given worker's total cumulative exposure was given by the sum of his intensity ${ }_{<25}$ and intensity $\geqslant 25$. Also tested was a set of three parameters using 25 and $100 \mu \mathrm{g} / \mathrm{m}^{3}$ as the cutoff levels.

\section{Summary of exposure parameters}

Using the methods described above, several different exposure parameters were constructed from each worker's exposure vector: total cumulative exposure, duration of employment, and cumulative exposure partitioned by time and intensity (table 3 ).

\section{Results}

Estimated job and year specific exposure levels were used to estimate lifetime exposure histories as just described. For presentation here, however, the 102 jobs were collapsed into 16 departments and the 40 year history of the plant summarised in four periods (table 4 and fig 3). The periods were chosen for the relative stability of exposure levels within each period. These groupings of departments and years were used only for presentation; in all analyses individual job year estimates were used. The considerable decline in

\begin{tabular}{|c|c|}
\hline Exposure parameter & Description \\
\hline Cumulative exposure & Sum of all annual exposures \\
\hline Current exposure & $\begin{array}{l}\text { Average exposure in the two years } \\
\text { before survey }\end{array}$ \\
\hline Years worked & Total duration of employment \\
\hline Cumulative exposure $_{1} 10$ & $\begin{array}{l}\text { Sum of all annual exposures in the } 10 \\
\text { years before survey }\end{array}$ \\
\hline Cumulative exposure $_{1120}$ & $\begin{array}{l}\text { Sum of all annual exposures } 11-20 \\
\text { years before survey }\end{array}$ \\
\hline $\begin{array}{l}\text { Cumulative exposure }{ }_{21} \\
\left(C E_{\geqslant 21}\right)\end{array}$ & $\begin{array}{l}\text { Sum of all annual exposures more than } \\
20 \text { years before survey }\end{array}$ \\
\hline Intensity $<25$ & $\begin{array}{l}\text { Sum of all exposures received in years } \\
\text { when average exposure was less than } \\
25 \mu \mathrm{g} / \mathrm{m}^{3}\end{array}$ \\
\hline Intensity $\geqslant 25$ & $\begin{array}{l}\text { Sum of all exposures received in years } \\
\text { when average exposure was more } \\
\text { than } 25 \mu \mathrm{g} / \mathrm{m}^{3}\end{array}$ \\
\hline
\end{tabular}
exposure levels with time is apparent, generally about one order of magnitude from the earliest to the most recent period (table 4). Until the 1960s, beryllium levels consistently exceeded the eight hour TWA

Table 3 Exposure parameters for use in exposure-response models of respiratory effects of beryllium 
88

standard of $2.0 \mu \mathrm{g} / \mathrm{m}^{3}$, and in the dirtiest departments (those engaged in calcining, sintering, and other operations involving furnaces) the air levels averaged well above the current peak level of $25 \mu \mathrm{g} / \mathrm{m}^{3}$, a level that should not be exceeded for more than 30 minutes. Nevertheless, low exposure jobs did exist, even in the early period, in such departments as inspection, laboratories, and shipping and receiving. For workers in some of these departments the principal sources of exposure in the early 1960s were probably cross

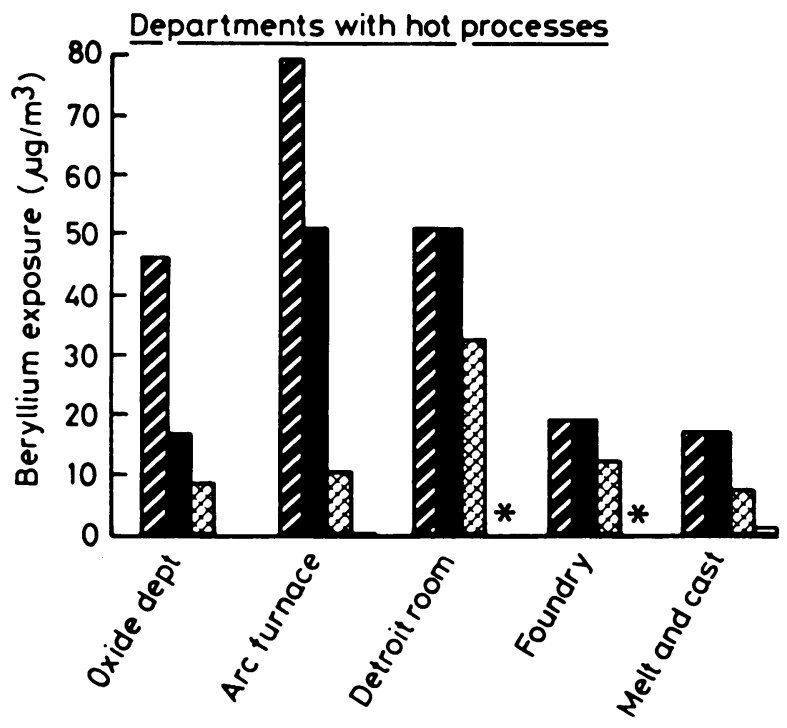

Departments with mixed exposures

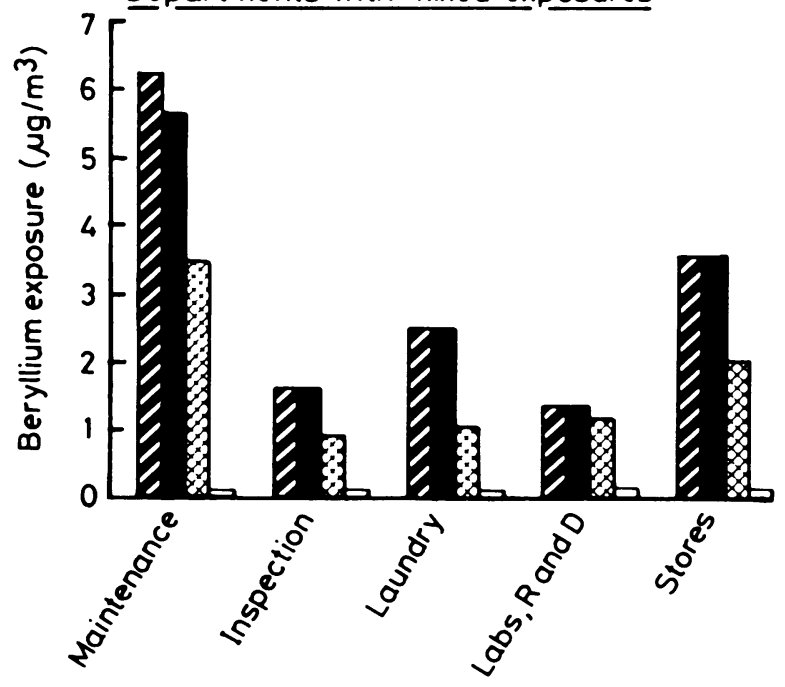

Kriebel, Springe, Eisen, Greaves contamination of common areas such as the lunch room and lockers. ${ }^{11}$

Departments were divided into three groups based on the expected particle size of beryllium in the air: those with the predominant beryllium exposure from hot processes (beryllium fume), those with the primary exposure from cold processes (beryllium dust), and those with mixed exposures. Departments that containe hot processes tended to have high air levels of beryllium (fig 3 ). The most serious industrial hygiene
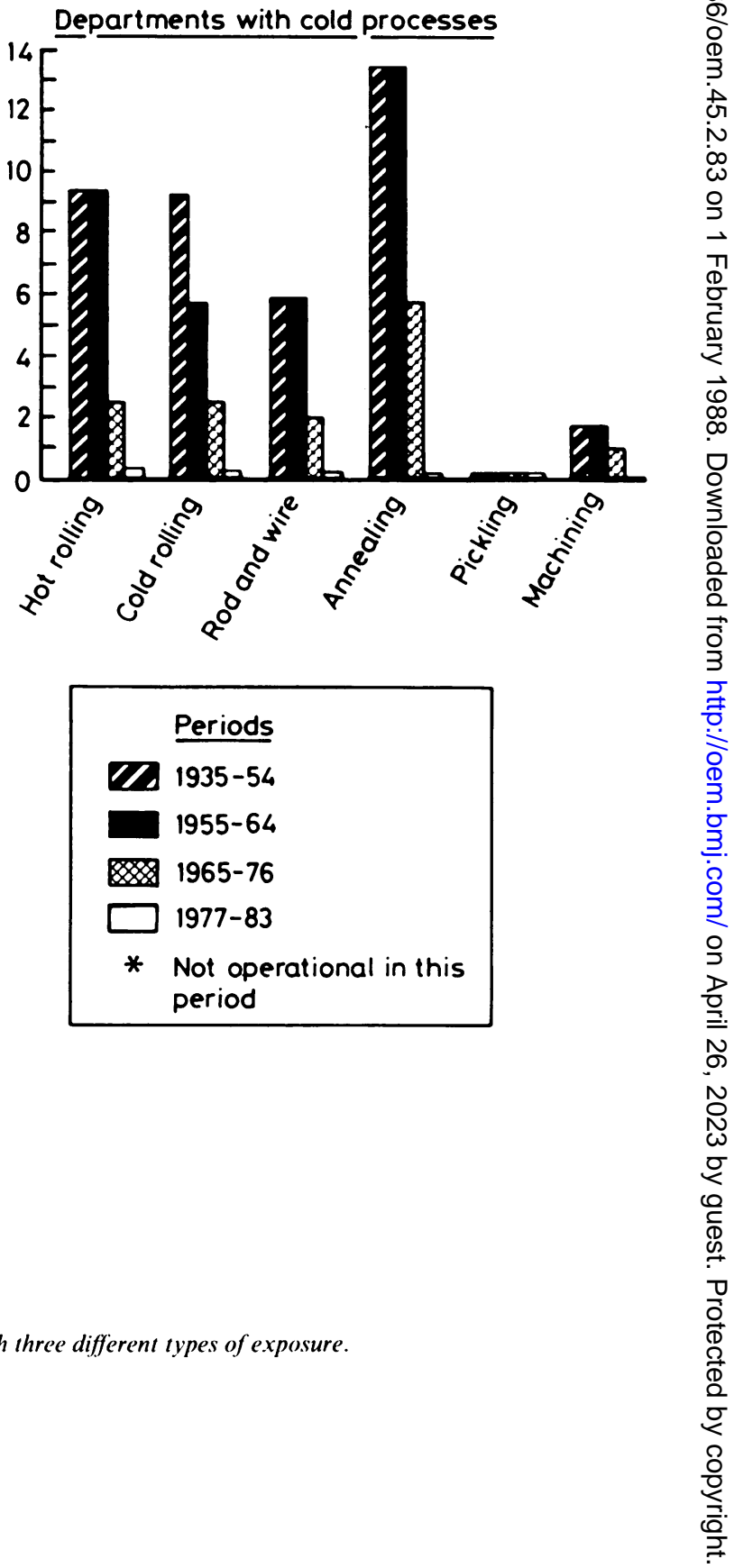
Pulmonary function in beryllium workers: assessment of exposure

Table 4 Summary of daily weighted average exposure levels $\left(\mu \mathrm{g} / \mathrm{m}^{3}\right)$ for 16 departments* in four periods

\begin{tabular}{|c|c|c|c|c|c|c|}
\hline \multirow[b]{2}{*}{ Department } & \multirow{2}{*}{$\begin{array}{l}\text { Approximate } \\
\text { No of } \\
\text { workers } \dagger\end{array}$} & \multirow{2}{*}{$\begin{array}{l}\text { No of jobs in } \\
\text { department }\end{array}$} & \multicolumn{4}{|l|}{ Period } \\
\hline & & & $1935-54$ & $1955-64$ & $1965-76$ & $1977-83$ \\
\hline $\begin{array}{l}\text { Oxide } \\
\text { Arc furnace room } \\
\text { Detroit furnaces } \\
\text { Foundry } \\
\text { Melt and cast } \\
\text { Hot rolling } \\
\text { Cold rolling } \\
\text { Rod and wire } \\
\text { Annealing } \\
\text { Pickling } \\
\text { Machining, grinding } \\
\text { Maintenance } \\
\text { Inspection } \\
\text { Laundry } \\
\text { Labs, R and D } \\
\text { Stores, shipping }\end{array}$ & $\begin{array}{r}46 \\
26 \\
24 \\
27 \\
105 \\
19 \\
29 \\
39 \\
10 \\
11 \\
60 \\
73 \\
12 \\
-28 \\
20\end{array}$ & $\begin{array}{r}14 \\
6 \\
4 \\
5 \\
6 \\
8 \\
8 \\
8 \\
5 \\
3 \\
5 \\
13 \\
7 \\
1 \\
6 \\
3\end{array}$ & $\begin{array}{l}46 \\
80 \\
51 \\
19 \\
18 \\
9 \cdot 3 \\
9 \cdot 2 \\
5 \cdot 9 \\
13 \\
0 \cdot 2 \\
1.7 \\
6 \cdot 2 \\
1.6 \\
2.5 \\
1.4 \\
3.6\end{array}$ & $\begin{array}{l}16 \\
51 \\
51 \\
19 \\
18 \\
9 \cdot 3 \\
5.7 \\
5.9 \\
13 \\
0.2 \\
1.7 \\
5.7 \\
1.6 \\
2.5 \\
1.4 \\
3.6\end{array}$ & $\begin{array}{l}8 \cdot 8 \\
11 \\
33 \\
13 \\
7 \cdot 6 \\
2 \cdot 5 \\
2.5 \\
2 \cdot 0 \\
5 \cdot 7 \\
0 \cdot 2 \\
0 \cdot 9 \\
3 \cdot 5 \\
0.9 \\
1.0 \\
1.2 \\
2.0\end{array}$ & $\begin{array}{l}0.5 \\
0 \cdot 7 \\
\text { NA } \\
\text { NA } \\
1 \cdot 1 \\
0 \cdot 2 \\
0 \cdot 2 \\
0 \cdot 2 \\
0 \cdot 1 \\
0 \cdot 1 \\
0 \cdot 1 \\
0 \cdot 1 \\
0 \cdot 1 \\
0 \cdot 1 \\
0 \cdot 2 \\
0.1\end{array}$ \\
\hline Total for plant: & 529 & 102 & & & & \\
\hline
\end{tabular}

*Smaller departments were grouped for presentation.

+Data are for 1943.

$\ddagger$ Not applicable: these departments were not operational in this period.

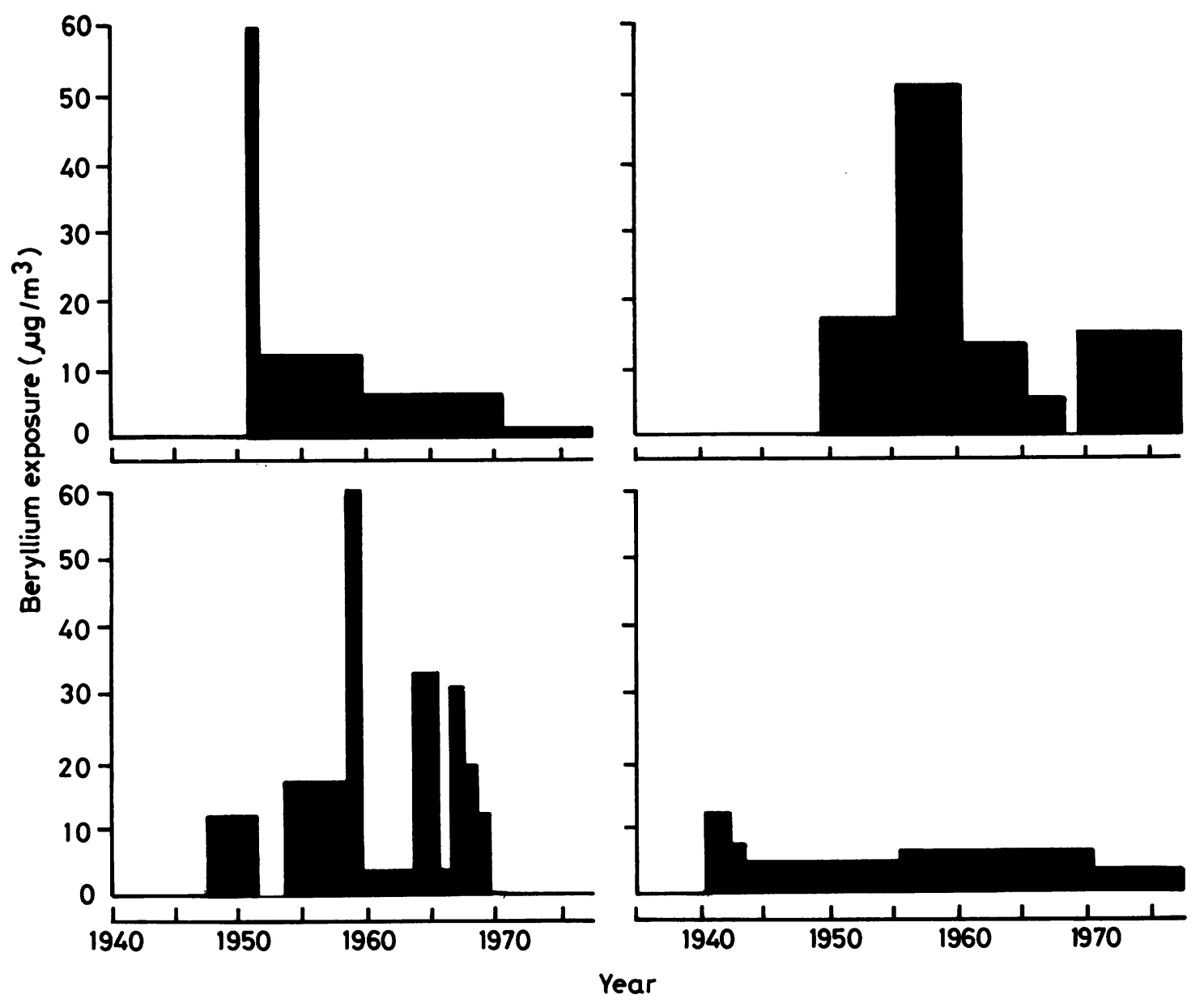

Fig 4 Beryllium exposure histories for four representative workers. 
Table 5 Summary statistics on exposure parameters for 297 white men in the cohort

\begin{tabular}{llccc}
\hline & $\begin{array}{c}\text { Geometric } \\
\text { Mean }\end{array}$ & $\begin{array}{c}\text { Standard } \\
\text { deviation }\end{array}$ & Median & Range \\
\hline $\begin{array}{l}\text { Years worked } \\
\text { Cumulative } \\
\begin{array}{c}\text { exposure }\left(\mu \mathrm{g} / \mathrm{m}^{3}-\right. \\
\text { years })\end{array}\end{array}$ & 37 & 10 & 17 & $2-39$ \\
$\begin{array}{c}\text { Exposure in } 1977 \\
\left(\mu \mathrm{g} / \mathrm{m}^{3}\right)\end{array}$ & $0 \cdot 4$ & 10 & 65 & $0 \cdot 1-4400$ \\
$\begin{array}{c}\text { Mean lifetime } \\
\text { exposure }\left(\mu \mathrm{g} / \mathrm{m}^{3}\right)\end{array}$ & 3 & 6 & 0.4 & $0.01-49$ \\
\hline
\end{tabular}

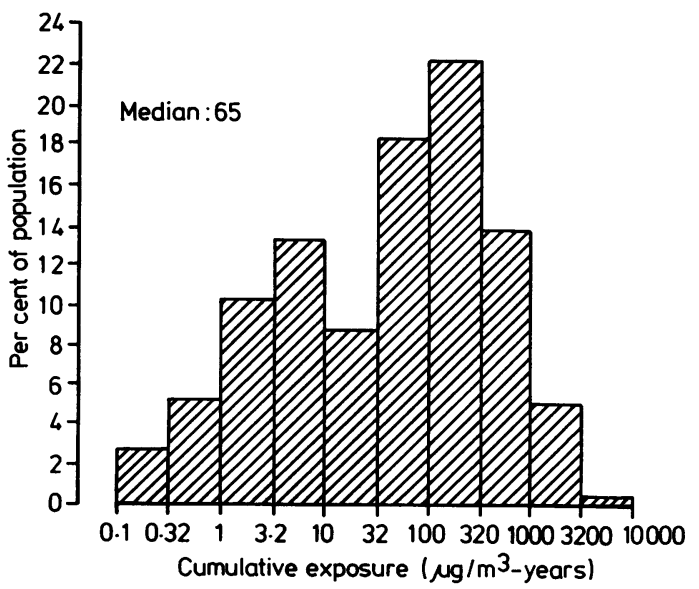

Fig 5 Distribution of cumulative exposure to beryllium for entire plant population $(n=309)$.

problems of this plant have always been in areas such as the arc furnaces, Detroit furnaces, and sintering, and calcining operations. Most of these high exposure operations were closed from about 1970.

Exposures to beryllium since 1977 were consistently below the standard of $2.0 \mu \mathrm{g} / \mathrm{m}^{3}$, and usually well below it.

The combination of greatly varying exposure levels over time and considerable job rotation (the average worker held three different jobs, whereas $25 \%$ of the workforce had five or more) meant that a large variety of patterns of exposure occurred in this population (fig 4). Cumulative exposure had a median value of $65 \mu \mathrm{g} /$ $\mathrm{m}^{3}$-years. Mean exposure, the average annual exposure level for a worker over his or her entire career, had a median value of $4.3 \mu \mathrm{g} / \mathrm{m}^{3}$. The mean and median number of years worked for this population was 17 (table 5).

The frequency distribution of cumulative exposure for the entire population was grouped in classes of equal size on the logarithmic scale for clarity of presentation (fig 5). The cumulative exposure data had an approximately log normal distribution.

\section{Discussion}

Accurate estimation of exposure to a given substance is crucial for the investigation of its possible health effects. Without valid exposure information, neither tests for the existence of an effect, nor estimation of its magnitude, may be performed accurately. Inaccurate exposure estimation is a common form of misclassification bias..$^{20}$ When the error in classification is nondifferential with respect to disease state, an underestimation of the exposure effect will result. ${ }^{21}$ In the extreme, exposure effects may be obscured entirely because of misclassification, even though an exposure effect actually exists.

There are two levels on which misclassification may operate in this study: in the retrospective determination of exposure levels and in the choice of an appropriate exposure parameter for use in exposure response models.

\section{MISCLASSIFICATION IN ESTIMATION OF EXPOSURE}

The industrial hygiene data were collected by several different agencies over a period of 40 years so some variation in methodology and accuracy was likely. Also, there were limited measurements for some jobs. The range of exposures over the plant's history and across jobs in the early years (when exposure data were sparse), however, was so great that the relative ranking of individual's exposures was probably valid even if considerable error was present.

The use of data collected by two different sampling methods introduced a potential source of error. Personal sampling data were used in this study to estimate job exposures, primarily from the late 1960s until 1977. In most jobs data were available from the AEC method for both the earlier and later periods. Figure 3 shows that the levels of exposure in the period covered by personal sampling were not only bracketed between the levels in periods measured by the AEC method but that the former lay on a fairly linear trend of falling exposures from the earliest to the most recent period. It seems reasonable, therefore, to use both sets of data, despite the difficulty of precisely converting the results from one method to the other.

Job histories were collected by worker interview and thus were subject to errors of recall. It is possible, for example, that sicker workers would recall their past work histories more accurately. This was unlikely to be a serious problem for several reasons. Firstly, workers were presented with a matrix listing all departments and all years and were required to account for their entire period of employment. This restrictive form of questioning should be more complete and less prone to recall bias than simply asking workers to list all the jobs they could remember. 
Secondly, the jobs themsleves were not used as indicators of exposure; instead, each job contributed a certain amount to the cumulative exposure estimate. Sick workers would have to remember jobs with high exposures to beryllium not just "dirty" jobs, in order to inflate artificially their cumulative exposure. The quality of the recalled job histories appeared quite good. Specific dates (such as the start of employment or periods of layoff) were often provided by the workers complete with day and month, even though such dates were not requested.

\section{MISCLASSIFICATION IN EXPOSURE PARAMETER SELECTION}

Valid exposure data summarised in an inappropriate exposure parameter may result in serious misclassification bias. For example, suppose a measure of lung function is affected by the peak levels of exposure rather than by the average level or the cumulative exposure. Then if the mean exposure was selected as the parameter in an exposure response model the model would fit poorly due to misclassification of exposure. Avoiding this form of misclassification requires an awareness of the pathophysiological mechanisms underlying the outcome measure(s) being studied.

Summation over the entire exposure history, $E_{i}$, for each worker is one of the simplest functions of an exposure history. It has desirable statistical and biological properties. Assuming that the minute ventilation of the lungs and the fraction of particles deposited in the lungs are approximately constant over time, Smith et al have shown that cumulative exposure is proportional to the cumulative dose to the lung. ${ }^{22}$ The major disadvantage of cumulative exposure, at least for certain toxins, is that it assumes equal potency for exposures experienced at any time whether these be recently or in the remote past; recent and past exposures, high exposures for a brief time, or low exposures over a long time are all weighted equally.

Because the response of the lung to beryllium is complex, probably including many time and concentration dependent processes, knowledge of how injury occurs is necessary so that the exposure data may be modelled to reflect the known toxic mechanisms. Exposure parameters carry with them assumptions about the physiological mechanisms of the disease process. These assumptions should manifest themselves in the form of the function chosen to summarise the exposure history. The design of exposure parameters should thus be seen as the selection of functions of exposure histories that express biologically important aspects of that history. By modelling exposure response relation with exposure parameters that have explicit biological assumptions behind them, it should be possible to learn more about the underlying disease process than if the parameters are chosen simply for statistical convenience.

Given the uncertainty surrounding the mechanisms of beryllium disease, and the paucity of data on the subclinical effects of the metal, a single "best" parameter cannot be chosen a priori. By testing a series of different parameters in exposure response models, however, some insights into the disease mechanisms may be gained. Hypoxaemia appears to be an acute effect of beryllium ${ }^{319}$ that might be related to recent exposures. Granulomatous parenchymal changes, on the other hand, are more likely to be related to long term exposure whereas recent exposures are relatively unimportant.

In summary, exposure modelling may be seen as an iterative process in which current knowledge of the pathophysiology of a disease suggests the form for exposure parameters, and the fit of these parameters, in turn, improves the understanding of the disease and its mechanisms.

We thank Mr Richard Chamberlin, former director of the Environmental Medical Service, Massachusetts Institute of Technology, for invaluable help in interpreting industrial hygiene data, and the physicians, technicians, and secretaries of the pulmonary unit of the Massachusetts General Hospital for their help with field work and numerous other aspects of the study.

Supported in part by a grant to the Harvard School of Public Health from the Mobil Foundation and by grant R03-0H01684 from the National Institute for Occupational Safety and Health. Dr Kriebel was supported by a training grant from the National Heart, Lung and Blood Institute, No T32 HL 0711809. Dr Sprince was supported in part by National Institute of Environmental Health Science grant R01 ES03301.

Requests for reprints to: Dr David Kriebel, Occupational Health Program, Harvard School of Public Health, 665 Huntington Ave, Boston, MA 02115 .

\section{References}

I Cullen MR, Cherniack MG, Kominsky JR. Chronic beryllium disease in the United States. Seminars in Respiratory Medicine 1986;7:203-9.

2 Sprince NL, Kazemi $\mathbf{H}$. US beryllium case registry through 1977. Environ Res 1980;21:44-7.

3 Kanarek DJ, Wainer RA, Chamberlin RI, Weber AL, Kazemi H. Respiratory illness in a population exposed to beryllium. Am Rev Respir Dis 1973;108:1295-1302.

4 Sprince NL, Kanarek DJ, Weber AL, Chamberlin RI, Kazemi H. Reversible respiratory disease in beryllium workers. $A m R e v$ 
Respir Dis 1978;117:1011-7.

5 Cotes JE, Gilson JC, McKerrow CB, Oldham PD. A long-term follow-up of workers exposed to beryllium. $\mathrm{Br} J$ Ind Med 1983;40:13-21.

6 Kriebel D, Sprince NL, Eisen EA, Greaves IA, Feldman HA, Greene RE. Beryllium exposure and pulmonary function: a cross sectional study of beryllium workers. $\mathrm{Br} \mathrm{J}$ Ind Med (in press).

7 Shilen J, Galloway AE, Mellor JF. Beryllium oxide from beryl: health hazards incident to extraction. Industrial Medicine 1944;13:464-9.

8 US National Institute for Occupational Safety and Health. Health hazard determination. Kawecki Berylco Industries, Inc. Cincinnati: USDHEW, NIOSH, 1976. (HHE report No 75-87-280.)

9 Donaldson HM, Shuler PJ. Trip report on visit to Kawecki Berylco, Reading, plant, 10/18/71. Washington: USDHHS, NIOSH Division of Surveillance Hazard Evaluation and Field Studies, (File 37.12.)

10 Shilen J, Koppenhaver FB, Cleland JG, Lutz LR, Vought VM. Beryllium extraction, reduction, and alloy fabrication-an engineering study covering ten years' experience. Industrial Medicine and Surgery 1954:23:291-9.

11 Health and Safety Laboratory. Occupational exposure to heryllium. Beryllium Corporation, Reading, PA. New York: New York Operations Office, Atomic Energy Commission, 1961. (Report No HASL 61-8B.)

12 Donaldson HM, Stringer WT. Beryllium sampling methods. $\mathrm{Am}$ Ind Hyg Assoc J 1980;41:85-90.
13 Breslin AJ, Harris WB. Health protection in beryllium facilities summary of ten years experience. New York: Health and Safety Laboratory Atomic Energy Commission, 1958. (Report No HASL-36.)

14 Still CW. Willis CP. Analytical chemistry. Journal of the American Chemical Society 1959;31:598.

15 National Institute for Occupational Safety and Health. Manual of analytical methods, 2nd ed. Vol 1. Cincinatti: DHEW, NIOSH, 1977:121-1 to 121-6. (Publ No 77-157A.)

16 Pennsylvania Department of Environmental Resources. Sampling data from survey of Kawecki Berylco, Reading, 2/8/72-2/22/72. Cincinatti: NIOSH Division of Surveillance Hazard Evaluation and Field Studies, 1972.

17 Kawecki Berylco Industries, Inc. Quarterly industrial hygiene monitoring data. Reading: KBI, 1980.

18 Kriebel D. Beryllium disease of the lung. Boston: Harvard School of Public Health, 1986. (Doctoral dissertation.)

19 Hall RH, Scott JK, Laskin S, Stroud CA, Stokinger HE. Acute toxicity of inhaled beryllium, III. Arch Ind Hyg Occup Med 1950:2:25-48.

20 Kleinbaum DG, Kupper LL, Morgenstern H. Epidemiologic research. London: Lifetime Learning Publications, 1982.

21 Greenland S. The effect of misclassification in the presence of covariates. Am J Epidemiol 1980;112:564-9.

22 Smith TJ, Hammond SK, Laidlaw F, Fine S. Respiratory exposures associated with silicon carbide production: estimation of cumulative exposures for an epidemiological study. $\mathrm{Br} J$ Ind Med 1984;41:100-8.

\section{Destruction of manuscripts}

From I July 1985 articles submitted for publication will not be returned. Authors whose papers are rejected will be advised of the decision and the manuscripts will be kept under security for three months to deal with any inçuiries and then destroyed. 